\title{
Produção de material didático complementar para aulas de anatomia humana do curso de nutrição
}

\author{
Production of complementary teaching material for human anatomy classes in the nutrition \\ course
}

\section{Producción de material didáctico complementario para clases de anatomía humana del curso de nutrición}

Silvia Cristina Figueira Olinto ${ }^{1 *}$ Luana Rossato $^{1}$, Ana Lucia Viana de Sousa ${ }^{1}$, Ariela Marques Parente $^{1}$, Josiani Pereira da Silva ${ }^{1}$, Luisa Caetano de Andrade ${ }^{1}$.

\section{RESUMO}

Objetivo: Relatar a experiência de produção de material didático complementar voltado ao curso de Nutrição, com ênfase nas estruturas constituintes do sistema digestório. Relato de Experiência: O material foi desenvolvido por monitores da disciplina de Anatomia Humana aplicada a Nutrição da Universidade Federal da Grande Dourados. Foram elaboradas 3 atividades complementares a serem realizadas de forma remota e/ou presencial: Atividade 1: Descrição de características anatômicas básicas sobre o órgão a ser estudado, apresentação de imagens cadavéricas com as principais estruturas a serem identificadas e tabela semiestruturada para a indicação dos nomes das estruturas marcadas nas imagens, posição anatômica e função/outras informações. A atividade 2 consistiu na adaptação de casos clínicos relacionados a temáticas sobre sistema digestório e questões para discussão. A atividade 3 foi elaborada para promover a fixação do conhecimento obtido das atividades 1 e 2. Considerações Finais: Espera-se que o desenvolvimento do material didático complementar auxilie os estudantes do curso de Nutrição durante o estudo da disciplina de Anatomia Humana, permitindo a compreensão da importância da utilização dos conceitos anatômicos na futura prática profissional.

Palavras-chave: Materiais de ensino, Anatomia, Sistema digestório.

\begin{abstract}
Objective: To implement didactic material for the teaching of the Human Anatomy, the present study aimed to describe the experience of producing complementary didactic material focused on the Nutrition course, with emphasis on the constituent structures of the digestive system. Experience Report: The material was developed by monitors from the discipline of Human Anatomy applied to Nutrition at the Federal University of Grande Dourados. Three complimentary activities were developed to be carried out remotely and / or presently: Activity 01: Description of basic anatomical characteristics about the organ to be studied, presentation of cadaveric images with the main structures to be identified and a semi-structured table for the indication the names of the structures marked in the images, anatomical position and function / other information. Activity 2 consisted in the adaptation of clinical cases related to themes on the digestive system. Activity 3 was designed to promote the fixation of the knowledge obtained from activities 1 and 2 . Final Considerations: It is expected that the development of the complementary didactic material will assist students in the Nutrition course during the study of the Human Anatomy discipline, allowing the understanding of the importance of using anatomical concepts in future professional practice.
\end{abstract}

Keywords: Teaching materials, Anatomy, Digestive system.

\section{RESUMEN}

Objetivo: Con el fin de implementar recursos didácticos para la enseñanza de la disciplina de Anatomía Humana, el presente estudio tuvo como objetivo reportar la experiencia de producir material didáctico complementario enfocado en el curso de Nutrición, con énfasis en las estructuras constituyentes del sistema digestivo. Informe de Experiencia: El material fue elaborado por monitores de la disciplina de Anatomía Humana aplicada a la Nutrición de la Universidad Federal de Grande Dourados. Se desarrollaron 03 actividades complementarias para ser realizadas de forma remota y / o presencial: Actividad 01: Descripción de las características anatómicas básicas del órgano a estudiar, presentación de imágenes cadavéricas con las principales estructuras a identificar y una tabla semiestructurada para la indicación los nombres de las estructuras marcadas en las imágenes, posición anatómica y función / otra información. La actividad 02 consistió en la adaptación de casos clínicos relacionados con temas del aparato digestivo. La Actividad 03 fue diseñada para promover la fijación de los conocimientos obtenidos de las actividades 01 y 02 . Consideraciones Finales: Se espera que el desarrollo del material didáctico complementario ayude a los estudiantes en el curso de Nutrición durante el estudio de la disciplina de Anatomía Humana, permitiendo la comprensión la importancia de utilizar conceptos anatómicos en la futura práctica profesional.

Palabras clave: Materiales de enseñanza, Anatomía, Sistema digestivo.

${ }^{1}$ Universidade Federal da Grande Dourados, Dourados - MS. *E-mail: silviafigueira@ufgd.edu.br 


\section{INTRODUÇÃO}

A Anatomia é uma das mais antigas ciências médicas básicas. De maneira abrangente permite estudarmos macro e microscopicamente a constituição e o desenvolvimento dos seres organizados (COSTA GB, et al., 2012). É considerada um componente básico da matriz curricular dos cursos da área de saúde, dentre eles o curso de Nutrição. Seu estudo permite entender a organização dos sistemas pelo estudo e reconhecimento da morfologia, localização e função dos órgãos (SALBEGO C, et al., 2015).

O estudo da ciência ocorre basicamente através de aulas teóricas bem como práticas. De maneira geral nas aulas teóricas o docente ministra conceitos sobre determinado tema anatômico, utilizando-se de livros, atlas, textos e figuras. Em contrapartida nas aulas práticas utilizam-se cadáveres que favorecem a visualização tridimensional da forma e a percepção de sua organização, textura além da localização dos órgãos bem como suas inter-relações com as demais estruturas que constituem o corpo humano (ARAUJO J, et al., 2014).

Apesar da utilização de cadáveres representar o modelo ideal por representar a própria matéria viva e real do objetivo do estudo da anatomia humana, a dificuldade na aquisição de cadáveres não reclamados é uma realidade nas instituições de ensino superior. A doação voluntária de corpos representa uma estratégia que pode ser utilizada no intuito de adquirirmos materiais para o estudo da ciência Anatomia, porém vários fatores como falta de conhecimento sobre o destino dos cadáveres e de informações sobre a legalidade do procedimento além de crenças religiosas influenciam a prática (FORNAZIERO CC, et al., 2010).

Mediante as dificuldades apontadas, cabe ao professor estimular os discentes com outras alternativas que possam facilitar o entendimento do conteúdo de forma integrada, fugindo da monotonia de apenas decorar estruturas. Nesse sentido, a utilização de materiais didáticos facilita o entendimento das aulas teóricas e aumenta o interesse dos estudantes pelo conteúdo, além de se tornar uma alternativa interessante para a aplicação no ensino da graduação (MOTA M, et al., 2010).

A ausência de material didático especializado torna limitante o aprendizado, principalmente na área morfológica. A utilização de metodologias ativas permite uma prática pedagógica modernizada e mais conectada com os alunos, inúmeras opções para aprender, tornando a aplicação vantajosa quando comparada somente ao modelo tradicional de ensino. O aluno é o centro do processo de ensinoaprendizagem, o autor do seu próprio conhecimento (SANTOS JW, et al., 2017).

Assim, o desenvolvimento de alternativas metodológicas para o ensino da Anatomia Humana permitirá que o estudante participe de maneira ativa do seu processo de aprendizagem, estimulando-o a ter pensamento crítico e reflexivo sobre os seus próprios métodos de estudo. Porém, a escolha do método é essencial para motivar e envolver os discentes uma vez que cada proposta possui diferentes fundamentos e aplicações. (FORNAZIERO CC, et al., 2010; NEVES MVS, 2010).

O isolamento social provocado pela propagação do SARS CoV 2 - Covid 19 demandou mudanças cotidianas, inclusive na área da educação. Algumas estratégias e alternativas foram implementadas por algumas Instituições durante a realização das aulas a distância permitindo que os discentes continuassem o estudo com os professores ou monitores da disciplina (GUSSO HL, et al., 2020).

Com o intuito de contribuir com a disciplina Anatomia Humana o presente trabalho relata a experiência de produção de material didático complementar a ser aplicado no curso de Nutrição, visando oferecer alternativas complementares para implementar o estudo da disciplina.

\section{RELATO DE EXPERIÊNCIA}

\section{Cenário, Sujeitos, Instrumento da Pesquisa e Estratégias utilizadas}

A ideia da elaboração do material de ensino complementar para a disciplina de Anatomia Humana surgiu durante o período em que houve a paralização das atividades presenciais da disciplina em virtude da pandemia pelo SARS CoV 2 - Covid 19. 
A intenção foi produzir um material que pudesse ser utilizado a distância e que complementasse o ensino prático bem como teórico quando as atividades retornassem na Universidade. Para tal, as professoras responsáveis pela disciplina juntamente com as monitoras do curso de Nutrição da Universidade Federal da Grande Dourados (UFGD-MS) desenvolveram durante os meses de Março a Setembro de 2020 materiais voltados a importante temática do curso, o sistema digestório.

Durante esse período, reuniões semanais foram realizadas (via Google- Meet) no intuito de revisar e orientar todas as etapas até a confecção do presente manuscrito. Durante as reuniões abordou-se conteúdos anatômicos do tema proposto bem como artigos voltados a área de educação.

Após revisões de conceitos básicos dos autores: Dangelo JG e Fattin CC (2011) complementadas com bibliografias da área (livros textos e atlas) e escolha das metodologias educacionais, as alunas organizaram o material em três atividades.

$\mathrm{Na}$ atividade 1 as monitoras elaboraram roteiros teórico-práticos contemplando as principais estruturas do sistema digestório: boca, língua, fauces, faringe, esôfago, estômago, intestino delgado, intestino grosso, reto e ânus. O material didático foi adaptado da metodologia desenvolvida por Carvalho CA (2017).

A proposta inicia com uma breve descrição do tópico a ser estudado: etimologia da palavra, tamanho e forma do órgão, a seguir foram adicionadas imagens cadavéricas do Guia de Anatomia Asclépio ( $h$ ttp://guiadeanatomia.com/anatomia.html) com as principais estruturas anatômicas, selecionadas através de marcações com diferentes números. Para identificar as estruturas foi elaborada uma tabela com espaços a serem preenchidos com o nome da estrutura, posição anatômica, função e ou outras informações (Figura 1).

$\mathrm{Na}$ atividade 2 as alunas adaptaram casos clínicos e questões voltadas a temas sobre o sistema digestório. $\mathrm{Na}$ atividade 3 elaboraram um mapa conceitual semi-estruturado para que os alunos completassem com informações anatômicas e fisiológicas obtidas pelo estudo e/ou nas etapas 1 e 2 (Figura 2).

Figura 1 - Roteiro Teórico Prático- Estômago: A) Breve descrição do órgão a ser estudado; B) Fonte para consulta das imagens; C) Quadro semiestruturado para o preenchimento.

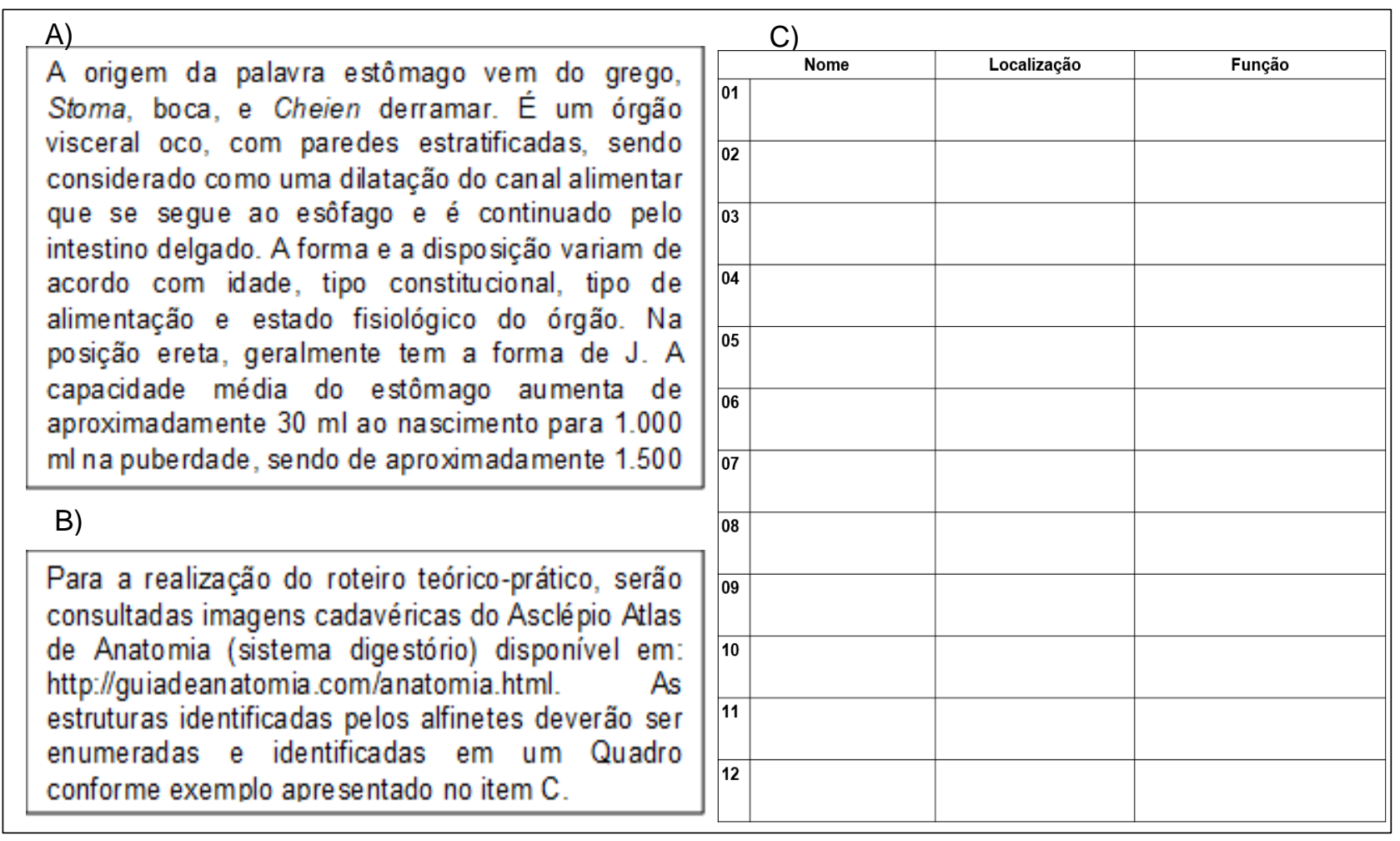

Fonte: Olinto SCF, et al., 2020. 
Figura 2 - Mapa conceitual semi-estruturado sobre sistema digestório.

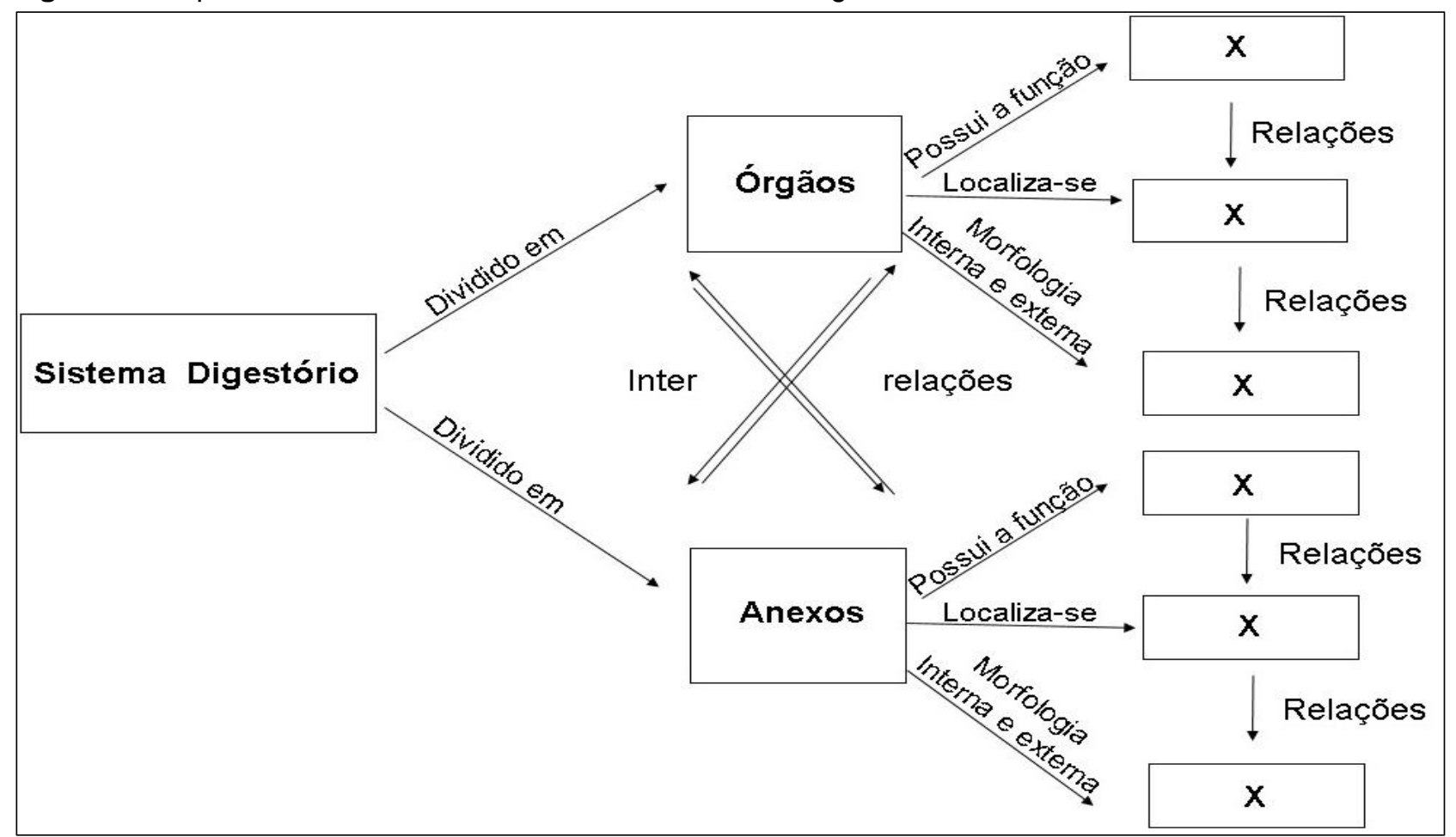

Fonte: Olinto SCF, et al., 2020.

\section{DISCUSSÃO}

O ensino da ciência Anatomia Humana nos dias atuais é cada vez mais desafiador. O conhecimento sobre o corpo humano desperta no aluno grande interesse, por outro lado o elevado número de estruturas para o estudo e suas correlações bem como a escassez de materiais para o estudo prático torna o ensino da ciência muitas vezes complicado e de difícil entendimento. A mediação do professor bem como a utilização de estratégias e materiais comprovadamente significativos no processo ensino-aprendizagem são poderosas ferramentas para minimizar essa problemática (MOREIRA MA, et al., 2012).

O papel do professor é de suma importância para que o aluno consiga conciliar essas dificuldades e não desista ou já crie uma barreira durante o processo de ensino-aprendizagem. A utilização de recursos didáticos complementares tem se mostrado muito eficaz nesse processo (JOHNSON EO, et al., 2012).

A ideia para a confecção do material proposto no presente trabalho consolidou-se em um momento onde as aulas nas instituições de ensino superior foram canceladas em decorrência da pandemia pelo Covid-19. A metodologia permitiu que as discentes (monitoras) revisassem os conceitos anatômicos teóricos bem como práticos e produzissem um material didático que poderá ser utilizado em um ambiente externo ao Laboratório de Anatomia Humana assim que as atividades da disciplina retornem na Universidade.

A breve introdução da Figura 1, citando características do órgão a ser estudado, previamente a demonstração da imagem cadavérica, permite que o discente inicie a construção do conhecimento assimilando as informações básicas pertinentes a cada órgão. A citação das características como peso, forma, tamanho e nomina anatômica permite ao estudante construir uma ideia espacial do órgão que será visualizado em seguida. Estudos prévios demostram que a aprendizagem só é considerada significativa se existir a assimilação de novas proposições por meio de estruturas cognitivas pré-existentes, facilitando assim, o estabelecimento de conceitos sólidos (GOMES AP, et al., 2011).

De acordo com Justina LA e Ferla MR (2006), uma estrutura quando utilizada como referência a uma imagem impressa permite materializar uma ideia ou um conceito, tornado, assim, o conhecimento da referida imagem mais assimilável. A inclusão dos dados nas tabelas sobre nome, posição e função promove a integração de informações que são fundamentais para o entendimento do sistema proposto. 
Em seguida propomos a atividade 2, que consiste em casos clínicos relacionados a temática sobre sistema digestório. Segundo Colares MAM, et al. (2019), a problematização bem como a aprendizagem baseada em problemas oferecem alternativas de ensino dos conteúdos teórico e prático. A leitura e discussão dos casos clínicos permite que os alunos tenham um primeiro contato com patologias ou situações que acometem órgãos específicos do sistema digestório, transpondo o conhecimento adquirido na disciplina de Anatomia Humana, para sua futura prática clínica. Estudos demostram que os estudantes ao serem colocados frente aos casos clínicos, passaram a pensar de forma mais reflexiva em busca de encontrar uma solução para os questionamentos, contribuindo para uma melhor capacidade resolutiva.

No momento que o aluno avança no estudo de um caso clínico, as relações, o significado funcional e as correlações de estruturas que pertencem a diferentes sistemas podem ser discutidas e revisadas facilitandoo a relacionar o conhecimento anatômico ao futuro profissional (ARSLAN OE, 2014).

Assim, a aplicação de problematizações torna a aprendizagem mais ativa e faz com que os discentes sejam submetidos a situações que os aproximem da realidade (PINTO ML, 2013). Os exemplos práticos permitem evidenciar também a aplicação da Anatomia no entendimento dessas condições para a adequada conduta do profissional nutricionista. Silva ARL, et al. (2017) reportou a importância da utilização de metodologias alternativas no processo do ensino-aprendizagem, uma vez que estimula o aluno a ter um senso crítico e participar de forma ativa durante o processo de construção do raciocínio.

A realização das questões que versam sobre particularidades anatômicas e funcionais básicas permite que os alunos revisem todo o conteúdo sobre o sistema digestório. A proposta da atividade final estimula os alunos a produzirem um mapa conceitual com os conteúdos assimilados após as realizações das atividades, verificando se algum ponto ou pontos específicos necessitam de mais estudos. Estudos prévios demostram a importância dos mapas conceituais no ensino da Anatomia Humana, contribuindo para a diminuição do acentuado índice de reprovação (SILVA JH, et al., 2018) (Figura 2).

Os organizadores gráficos são ferramentas que auxiliam na retenção e recuperação de informações durante o processo de aprendizagem, correspondem a diagramas hierárquicos, os quais mostram a organização e correspondência entre conceitos apresentados por uma diferenciação progressiva ou por uma reconciliação integrativa de conceitos (JUNIOR VC, 2013).

Como os mapas conceituais foram desenvolvidos no intuito de organizar o conhecimento e representá-lo de forma mais prática para o próprio individuo ou para outras pessoas, a ferramenta possui enorme potencial para o estudante uma vez que auxiliá-lo na formulação e avaliação de novos conceitos em relação ao aprendizado (SOUZA NA e BORUCHOVITCH E, 2010).

A utilização de mapas conceituais permite que o discente indique as relações entre conceitos incluídos em uma estrutura hierárquica de proposições, desenvolva o pensamento crítico, correlacione a teoria com a prática bem como a resolução de problemas, tornando significativa a ação pedagógica., oportunizando a identificação do (s) ponto (s) com fragilidade (s) de entendimento (FOUREAUX G, et al., 2018, MACHADO CT e CARVALHO AA, 2019).

\section{CONSIDERAÇÕES FINAIS}

É consenso, entre educadores e pesquisadores, a importância de uma educação de qualidade na formação e preparação dos discentes para a sociedade atual e, dentro desse contexto, o ensino da Anatomia Humana tem se tornando cada vez mais desafiador. Sabe-se que a utilização de estratégias didáticas complementares ao modelo de ensino tradicional incentiva o discente a ter autonomia na formação do conhecimento pois permite a compreensão do seu papel na construção do saber. Nesse sentido, relatamos as atividades realizadas pelas monitoras da disciplina Anatomia Humana que resultaram na produção de três atividades de ensino voltadas a temática sobre o sistema digestório. A utilização de roteiros teórico-prático com imagens cadavéricas, o estudo e discussão de casos clínicos-questões bem como o preenchimento do mapa conceitual permitirá que as futuras turmas experimentem diferentes formas para a construção do saber correlacionando as situações-conceitos anatômicos com a futura prática professional. Espera-se também que as atividades propostas incentivem a produção de outros materiais didáticos a cada monitoria. 


\section{AGRADECIMENTOS}

Agradecemos a professora Dra ${ }^{a}$. Daniela Cristina de Oliveira Silva, Professora da Disciplina de Anatomia da Universidade Federal de Uberlândia (ICBIM, UFU), os acadêmicos da Faculdade de Medicina da Universidade Federal de Uberlândia (UFU): Alan Bartasson Ferreira Rosa, Pedro Zerri David e também ao Técnico do Laboratório de Anatomia (ICBIM, UFU) Lázaro Antônio dos Santos, por terem permitido a utilização de imagens cadavéricas obtidas do Guia de Anatomia Asclépio (http://guiadeanatomia.com/anatomia.html).

\section{REFERÊNCIAS}

1. AGUIAR JG, CORREIA PR. How to make good concept maps? Establishing benchmarks and proposing training activities. Revista Brasileira de Pesquisa em Educação em Ciências, 2013; 13(2):141-157.

2. ARSLAN OE. Region vs. system-based anatomy: efficacy and implementation. American International Journal of Biology, 2014; 2 (3): 01-23.

3. ARAÚJO JÚNIOR JP, et al. Desafio anatômico: uma metodologia capaz de auxiliar no aprendizado de anatomia humana. Medicina, Ribeirão Preto, 2014; 47(1):62-68.

4. CARVALHO CA. Utilização de Metodologia Ativa de Ensino nas Aulas Práticas de Anatomia. Revista de Graduação USP, 2017; 2(3):117-121.

5. COLARES MAM et al. Metodologias de ensino de anatomia humana: estratégias para diminuir as dificuldades e proporcionar um melhor processo de ensino-aprendizagem. Arquivos do MUD, 2019; 23(3):140-160.

6. COSTA GB, et al. O cadáver no ensino da anatomia humana: uma visão metodológica e bioética. Revista Brasileira de Educação Médica, 2012;36 (3): 369-373.

7. DANGELO JG, FATTINI CC. Anatomia sistêmica e segmentar. 3.ed. São Paulo: Atheneu, 2011;757p.

8. FORNAZIERO CC, et al. O ensino da anatomia: integração do corpo humano e meio ambiente. Revista Brasileira de Educação Médica, 2010; 34 (2): 290-297.

9. FOUREAUX G, et al. O ensino-aprendizagem da anatomia humana: avaliação do desempenho dos alunos após a utilização de mapas conceituais como uma estratégia pedagógica. Ciência \&. Educação, Bauru, $2018 ; 24$ (1), 95-110.

10. GOMES AP, et al. O Papel dos Mapas Conceituais na Educação Médica. Revista Brasileira de Educação Médica, $2011 ; 35(2): 275-282$.

11. GUIA DE ANATOMIA ASCLÉPIO. 2014. Disponível em:http://guiadeanatomia.com/anatomia.html.

12. GUSSO HL, et al. Ensino superior em tempos de pandemia: diretrizes à gestão universitária. Educação\& Sociedade, 2020; 41:1-26.

13. JOHNSON EO, et al. Modernization of an anatomy class: From conceptualization to implementation. A case for integrated multimodal-multidisciplinary teaching. Anatomical Sciences Education , 2012; 5 (6): 354-366.

14. JÚNIOR VC. A Utilização de Mapas Conceituais como Recurso Didático para a Construção e InterRelação de Conceitos. Revista brasileira de educação médica; 2013; 37 (3): 441-447.

15. JUSTINA LA, FERLA MR. A utilização de modelos didáticos no ensino de Genética - exemplo de representação de compactação do DNA eucarioto. Arquivo Mudi, 2006; 10 (2): 35-40.

16. MACHADO CT, Carvalho, AA. Os efeitos dos mapas conceituais na aprendizagem dos estudantes universitários. ETD-Educação Temática Digital, 2019; 21(1), 259-277.

17. MACHADO CT, CARVALHO AA. Mapa conceitual como ferramenta de aprendizagem no ensino superior. Revista Contexto \& Educação,2020; 35 (110): 187-201.

18. MOREIRA MA. Al final, que és aprendizaje significativo? Qurriculum. La Laguna, 2012; 25: 29-56.

19. MOTA MF, et al. A. Constructivist pedagogic method used in the teaching of human anatomy. International Journal Morphology; 2010: 28 (2), 369- 374.

20. NEVES MVS. Uma nova proposta no ensino da Anatomia Humana: desafios e novas perspectivas. Dissertação (Mestrado Profissional em Ensino de Ciências da Saúde e do Meio Ambiente). Centro Universitário de Volta Redonda, Volta Redonda, 2010;39 p.

21. PINTO ML. Práticas Pedagógicas no Ensino Superior. A aprendizagem baseada em problemas (ABP) ou Problem Based Learning (PBL) na área da saúde. Copyright ,2013;183-201.

22. SALBEGO C, et al. Percepções Acadêmicas sobre o Ensino e a Aprendizagem em Anatomia Humana, Revista Brasileira de Educação Médica, 2015; 39(1): 23-31.

23. SANTOS JW et al. Metodologias de ensino aprendizagem em anatomia humana. Ensino Em Re-Vista $2010 ; 24$ (2) 364-386.

24. SILVA ARL, et al. Metodologia ativa na educação.São Paulo: Pimenta Cultural, 2017; 150p.

25. SILVA JH, et al. O ensino-aprendizagem da anatomia humana: avaliação do desempenho dos alunos após a utilização de mapas conceituais como uma estratégia pedagógica. Ciência \& Educação, 2018; 24(1): 95-110.

26. SOUZA NA, BORUCHOVITCH E. Mapas conceituais: estratégia de ensino/aprendizagem e ferramenta avaliativa. Educação em Revista, 2010;.26(3):195-218. 